

\section{University of Arizona- College of the}

Bajhamas Team

u Unjversity of Arizona Heacled by Rijchard Stoffile

- Charles Bollong, Alex Carroll, Clinit Carroll, Fletcher ChmaraHujfi, Jill Dumbauld, Heather Faujand, Richard Gilmour, Arin Haverland, Cory Jones, Shawn Kelley, Noreen Lyell, Aja Martinez, Amanda Murphy, Nate OMeara, Kate Payne, Terra Pierce, Peter Poer, Dan Post, and Kathleen Van Vlack

College of the Bahamas Headed by Jessica Minnis - Kendra Arnet, Chervain Dean, Tarah McDonald, Ward Minnis, Yasmin Skinner, and Tavarrie Smith

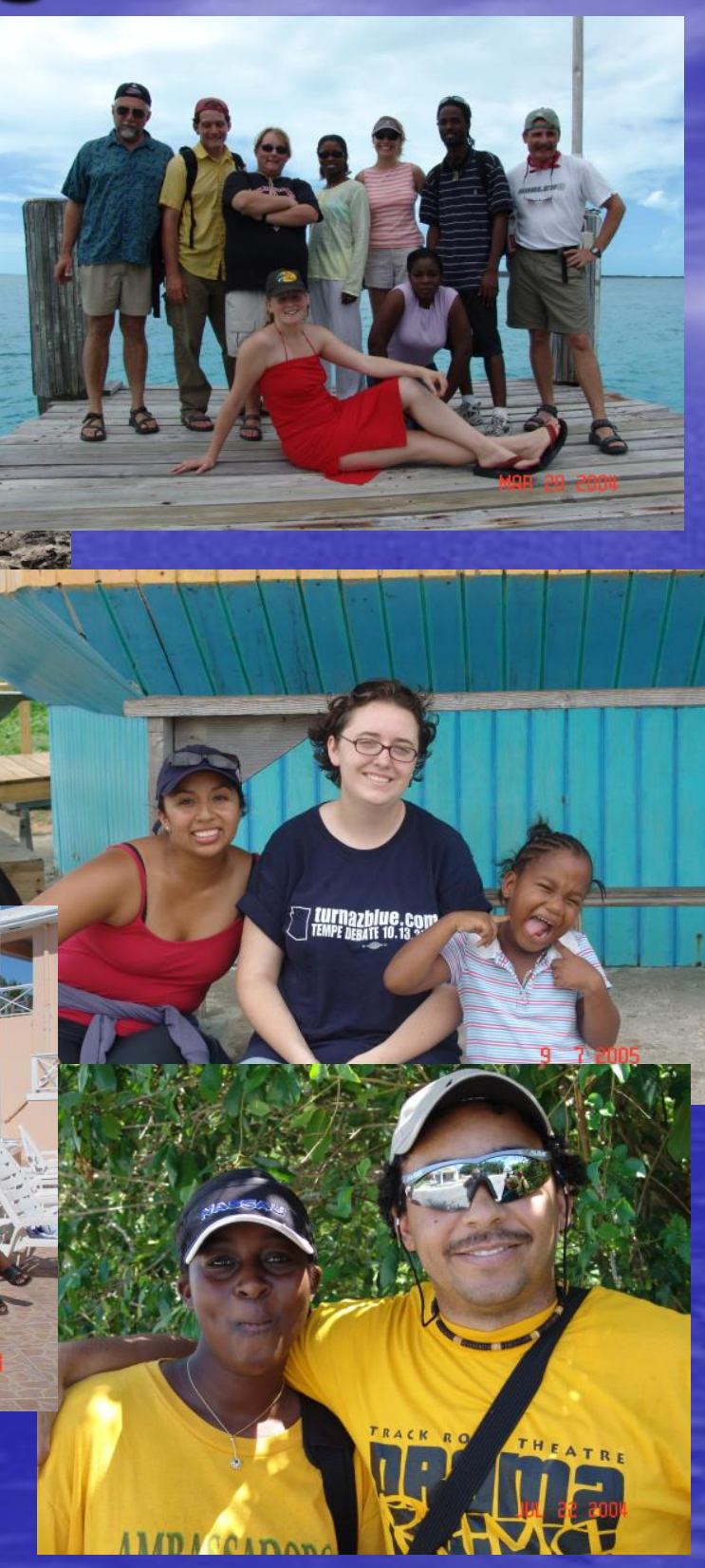




\section{BBP Study Purpose and Implijacations}

$\checkmark$ Purpose of trie BEP study is to understand, even model with paranseterized variables, why there were djfferent settlement responses to the three proposed MPAs in the Exumas.

$\checkmark$ It is not the puspose of the study to second guess or criticize the scjentists who prepared the MPA proposal, the Bahamian Government who approved the proposal, or the Department of Fisheries who has been charged with implementing the proposal.

- Social problerris associated with the MPA siting process in the Exumas were due to jnaclequate Socjal Impact Assessments (SIAS) Which were beyond the scope of the siting process.

If the MPA siting process had identified these social impacts, most could have been ssitigated thus increasing the probability of success. 


\section{Proposed Marine Protected Areas}

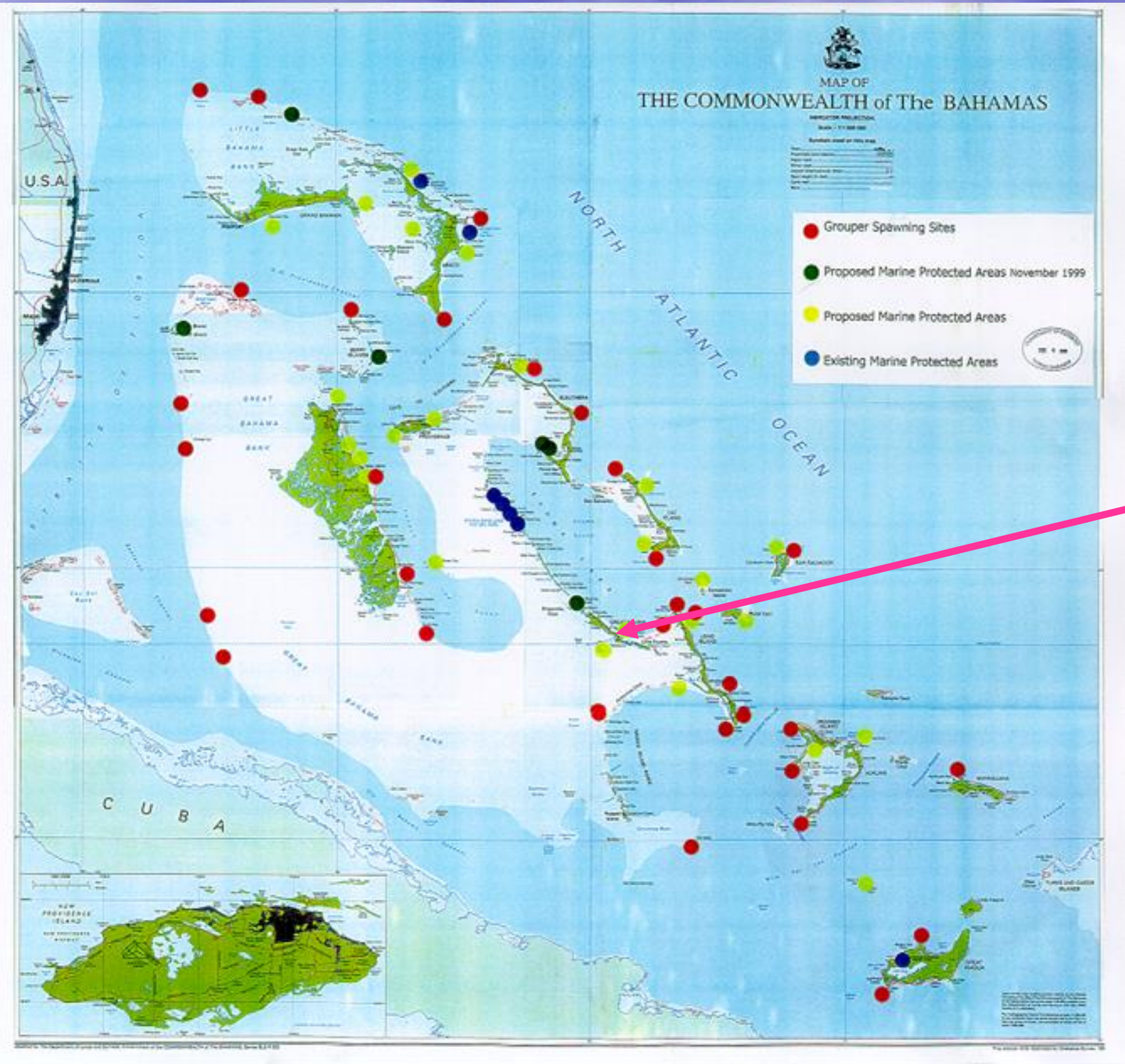

Exuma Islands and Cays 


\section{Proposed MPAs for Exuma}

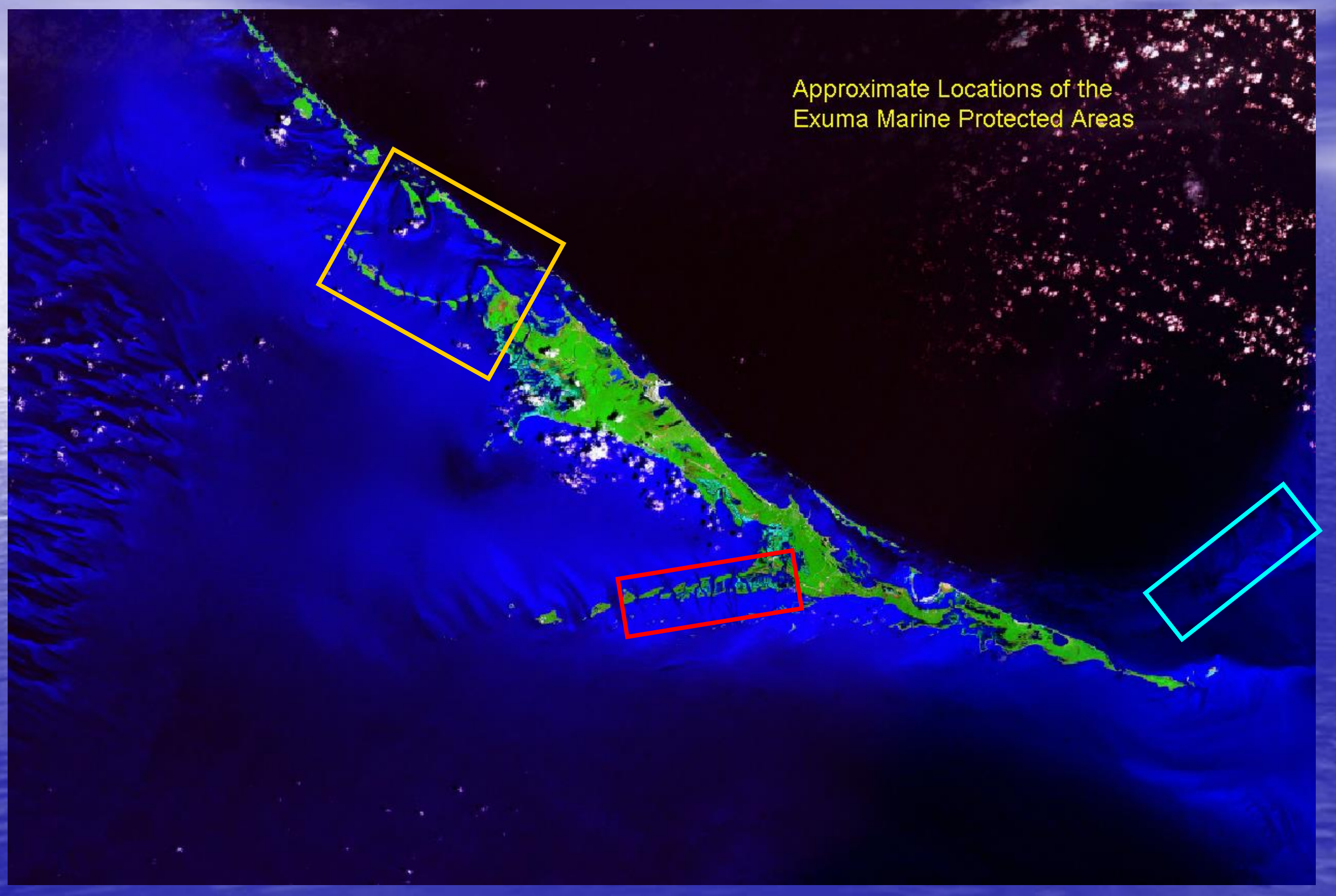




\section{Pre-Study There Were Different Settlement Responses to Nearby MPA Proposals}

- Northern Settlements $=$ negative response

- Middle Settlements = neutral response

- Southern Settlement $=$ positive response 


\section{Study Plan}

To conduct systematijc interviews in six "nearby settlements" that had been identified in the siting process as potentially most affected by one of the three proposed MPAs.

- Assume that the key response to an MPA proposal occurs at the settlement scale.

- Assume that all settlement members are potentially key in the final settement response.

- Assume that both fishers and non-fishers are key in the final settlement response.

- Assume that both males and females are key in the final settlement response. 


\section{Study Dața}

- Iterative Data collected in seven field sessions firom March 2002 to July 2005

- Sea Attachment Survey

- Quality of Life

- Grubbing

- Tourism

- Ethnobotany

- Land Use Mapping

- Sea Use Mapping

- Mix methods and triangulation of findlings. 


\section{Uof́A/CoB Study, Total Interviews}

Gender

Formal

Informal

Total

\begin{tabular}{|c|c|c|c|}
\hline Male & 174 & 138 & 312 \\
& & & 138 \\
\hline Female & 151 & 83 & 234 \\
\hline Total & 325 & 221 & 546 \\
\hline
\end{tabular}

SFAA 2006 


\section{A Shared Problem: A Declining Ocean}

- People interviewed have noticed changes in the ocean over the last thirty years.

- During Quality of Life interviews

$-68.5 \%$ of 127 respondents believe the ocean is worse off today in relation to the past.

- These responses indicate that even though there has been a decline in ocean condition, it can still support sustainable local resource extraction. 


\section{Shared Solution: MPAs}

- During the Quality of Life interviews people were asked "Would you be willing to support some kind of MPA near your settlement?"

- Almost all of the 123 respondents were outright or conditionally positive about having an MPA:

- $73(59.3 \%)$ yes

- $49(39.8 \%)$ maybe

$1(.8 \%)$ no

These data document overwhelming support for establishing a nearby MPA, while at the same time there were negative public responses by northern settlements.

- The underlying conditional support assumptions of MPA siting are key for explaining this apparent contradiction. 


\section{Modeling Variables}

Resilience

Identity

Agency 


\section{Modeling Variables: Agency}

$\checkmark$ Agerscy $=$ is a sense of personal and group power to have chosen goals supported and aittajned in the wider society.

$\checkmark$ It is a sense of control over the future of the cultural, social, economic, and environmental dimensions of one's life.

- Local settlement agency can either be increased or decreased through MPA design, placement process, and management. 


\section{Historic}

Background of

Local Agency
- The people of these traditional Exuma settlements enjoyed a high degree of cornirnunity control over their land \& sea from end of slavery in 1832 until the $1950^{\circ}$ s.

- The 1950s brought more goverrirnerit control, the usurping of traditional land and sea commons, as well as foreign yachters and tourist resorts.

- This trend of foreign and government occupation of family or traditional land continues today.

- Proposed MPAs and ecotourism projects can either increase or decrease local power over traditional use areas and the economy. 


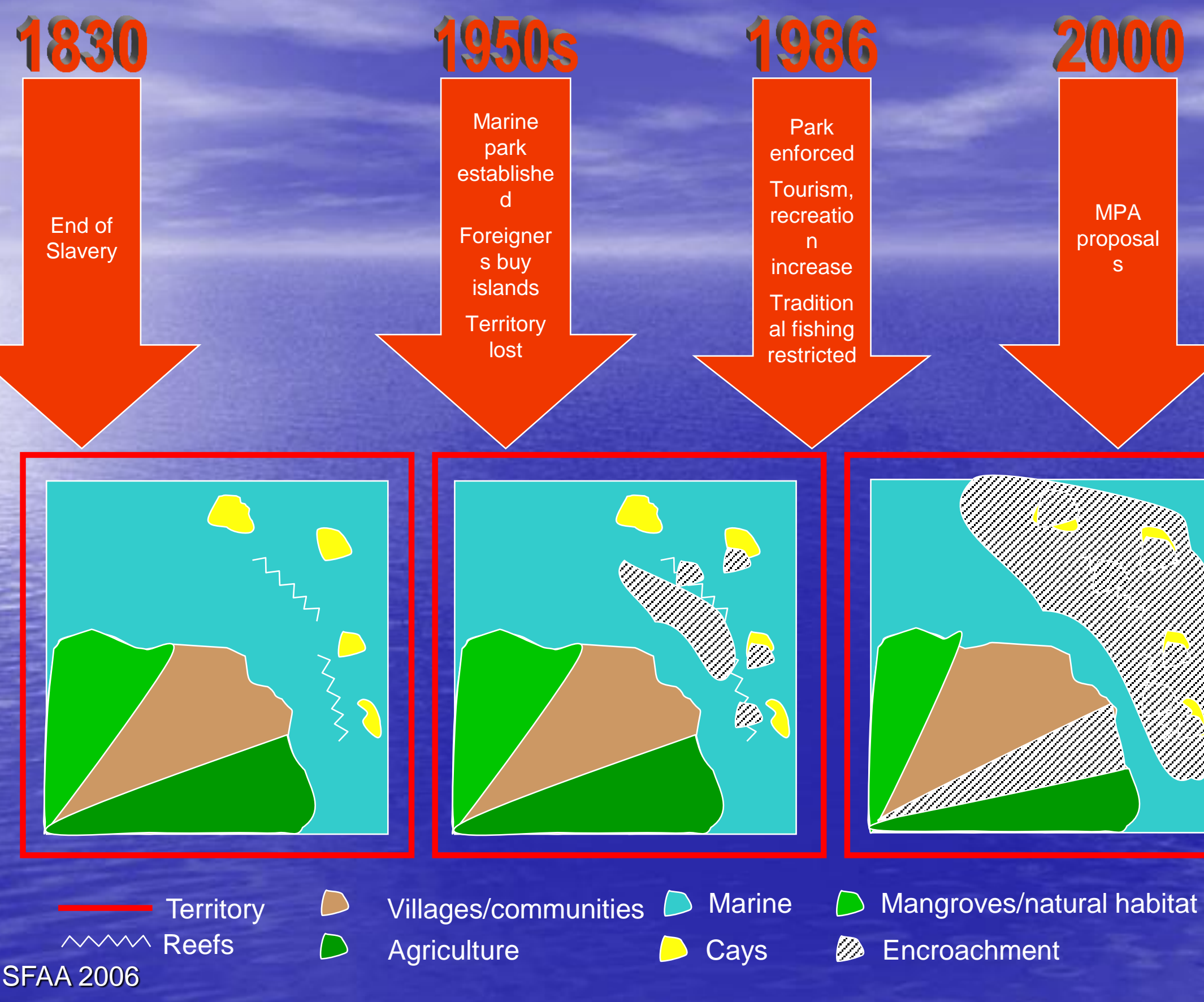




\section{Perceptions of Community Agency:}

Quality of Life Survey, Present Satisfaction $\mathbb{N}=140$, Response $=131$

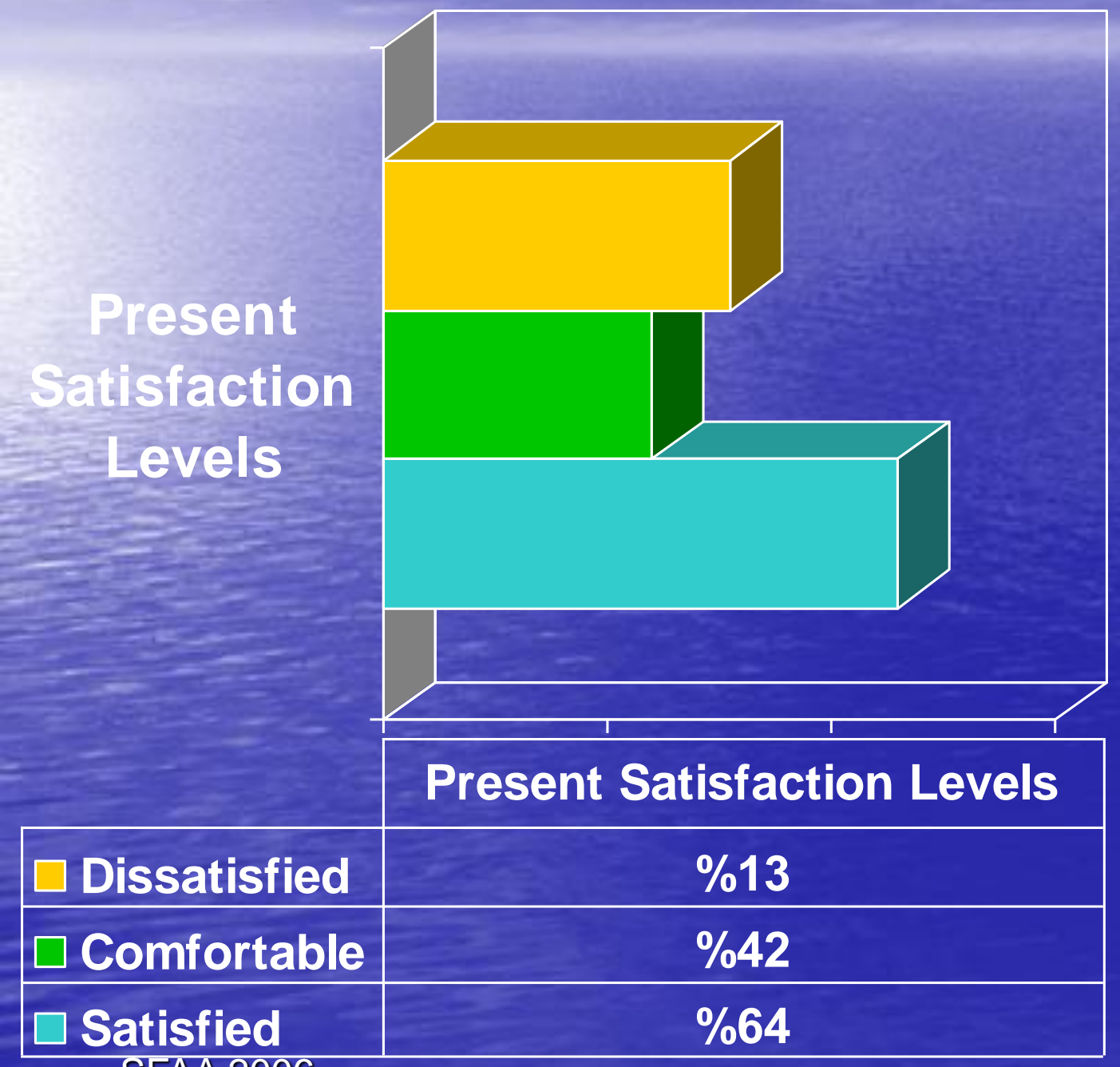

Defined as freedom from external control and the ability for individuals to influence the outcome of events .

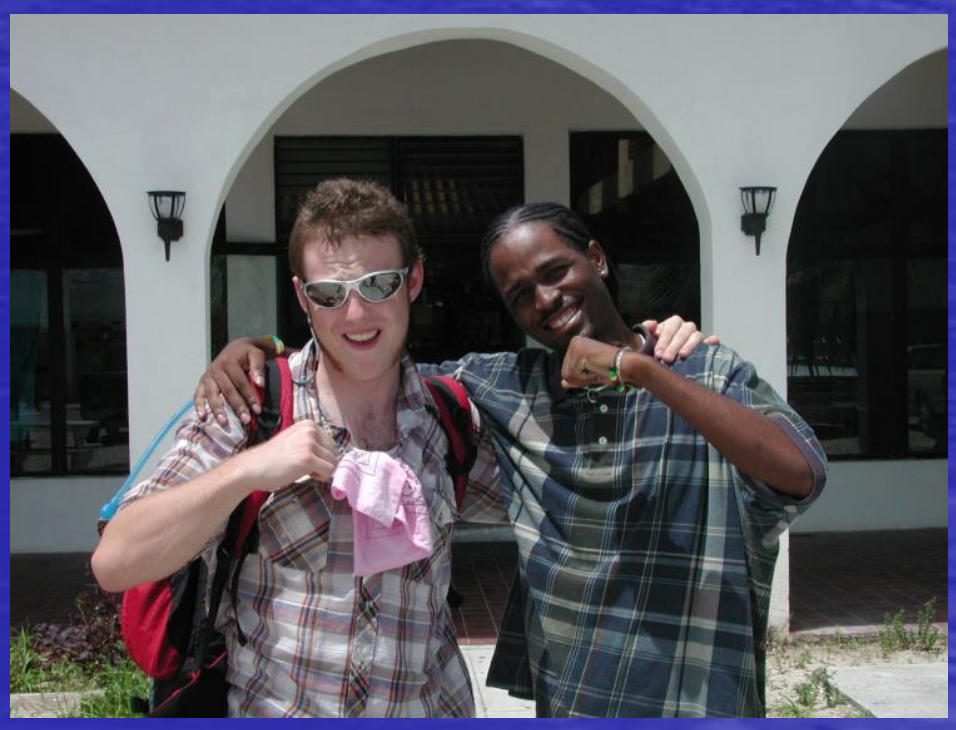




\section{Modelling Variables: Resiljence}

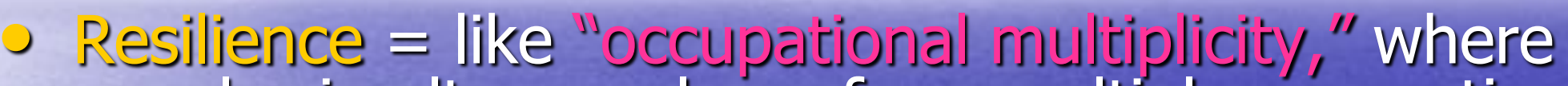
people simultaneously perform multiple occupations in antjcjpation that one or more will fail (Comitas 1973),

u "environırserjial use mulcjplicity" has both subsistence and commercial dimensions which are all maintained on the assumption that some will be there to provide the basics of life when others fail during commercial boom and bust cycles.

- Local settlement resilience can either be increased or decreased depending on the extent that the MPA supports or diminishes traditional environmental use multiplicity. 


\section{Modeling Variables: Identity}

$\checkmark$ Seritenent Identity (Who We Are) $=$ the traditional coastal settlensents of the Exumas are connected in multistranded ways to thejr local sea and it has become culfurally central in their lives.

$\checkmark$ Settjement are connected to the sea through the following cultural comains

1. Material arts

2, sea biology

3. Underwater landscapes

4. Land biology

5. Expressive Arts

6. Identity Symbols

7. Settlement Stories

- Settlement identity can either be increased or decreased by an MPA to the extent that it strengthens or decreases access to places and resources needed to sustain activities in the above cultural domains. 


\section{The Proposed MPAs}

$\checkmark$ The following section discusses each of the proposed Exuma MPAs in light of the UofA \& COB research findings. 


\section{Northern MPA}

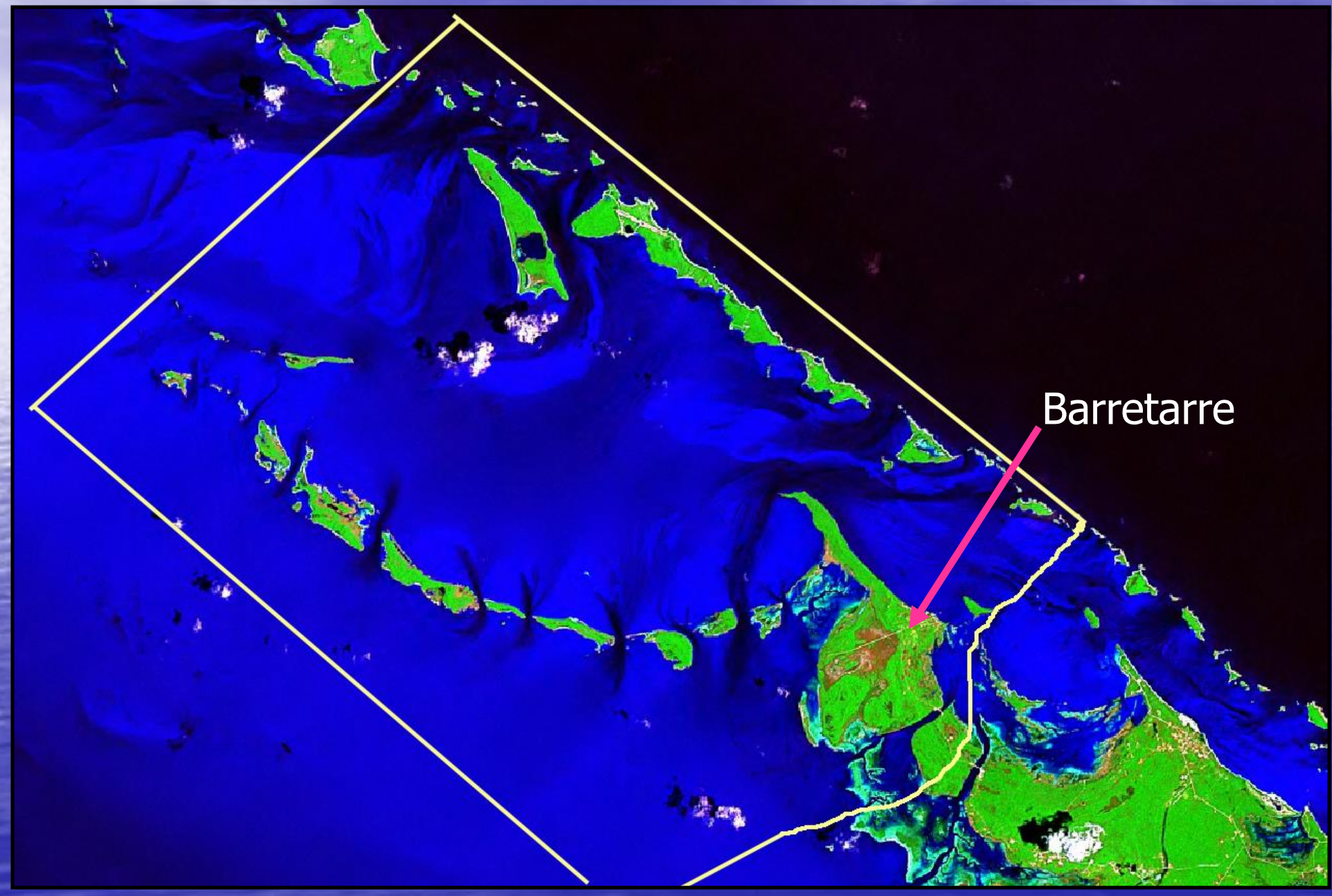

Local Responses:

- It eliminates fishing for cash.

-It eliminates subsistence fishing.

- It removes us from control over our sea.

-It is not for us, but instead for western science. 


\section{Centital MPA}

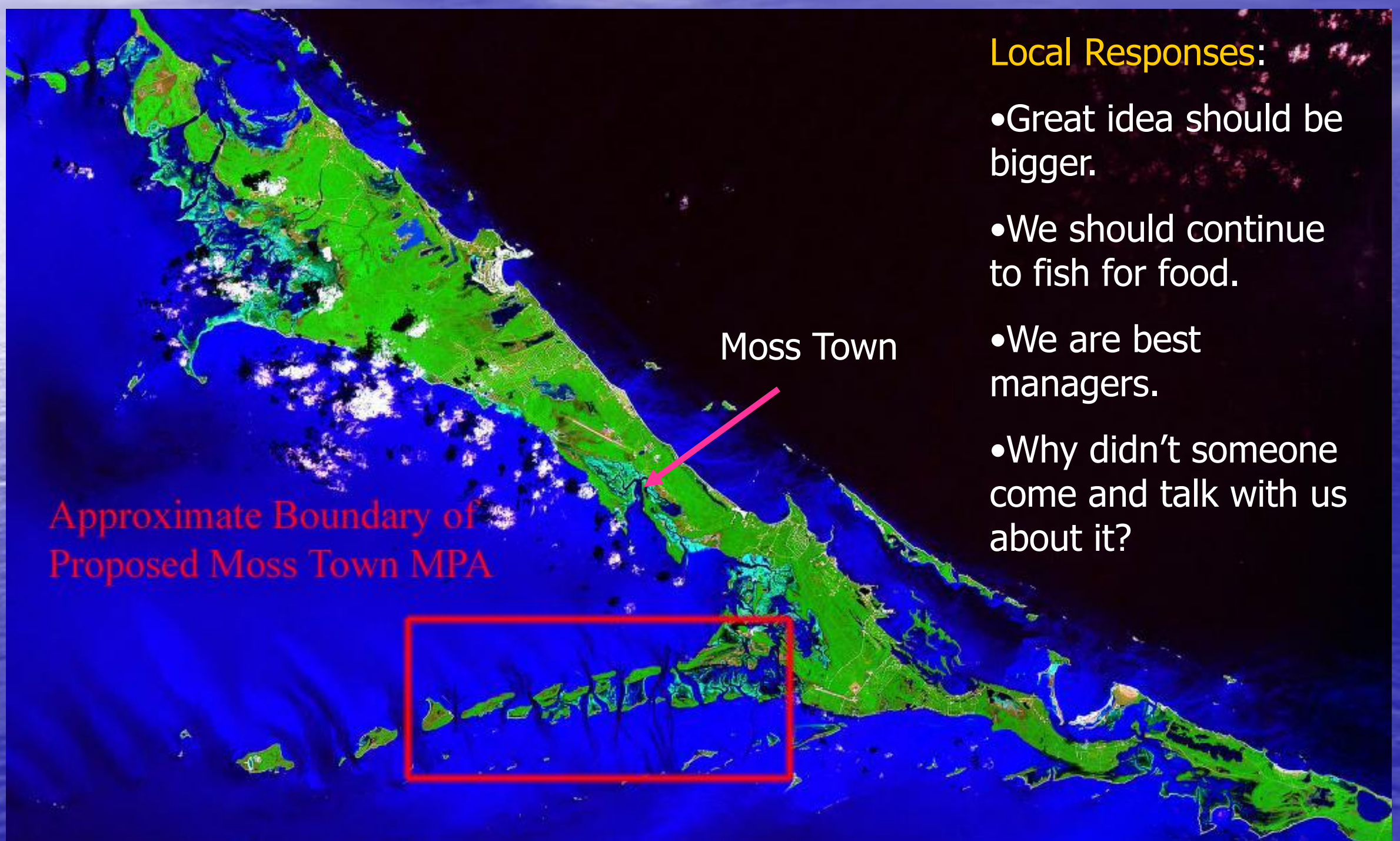




\section{Southern MPA}

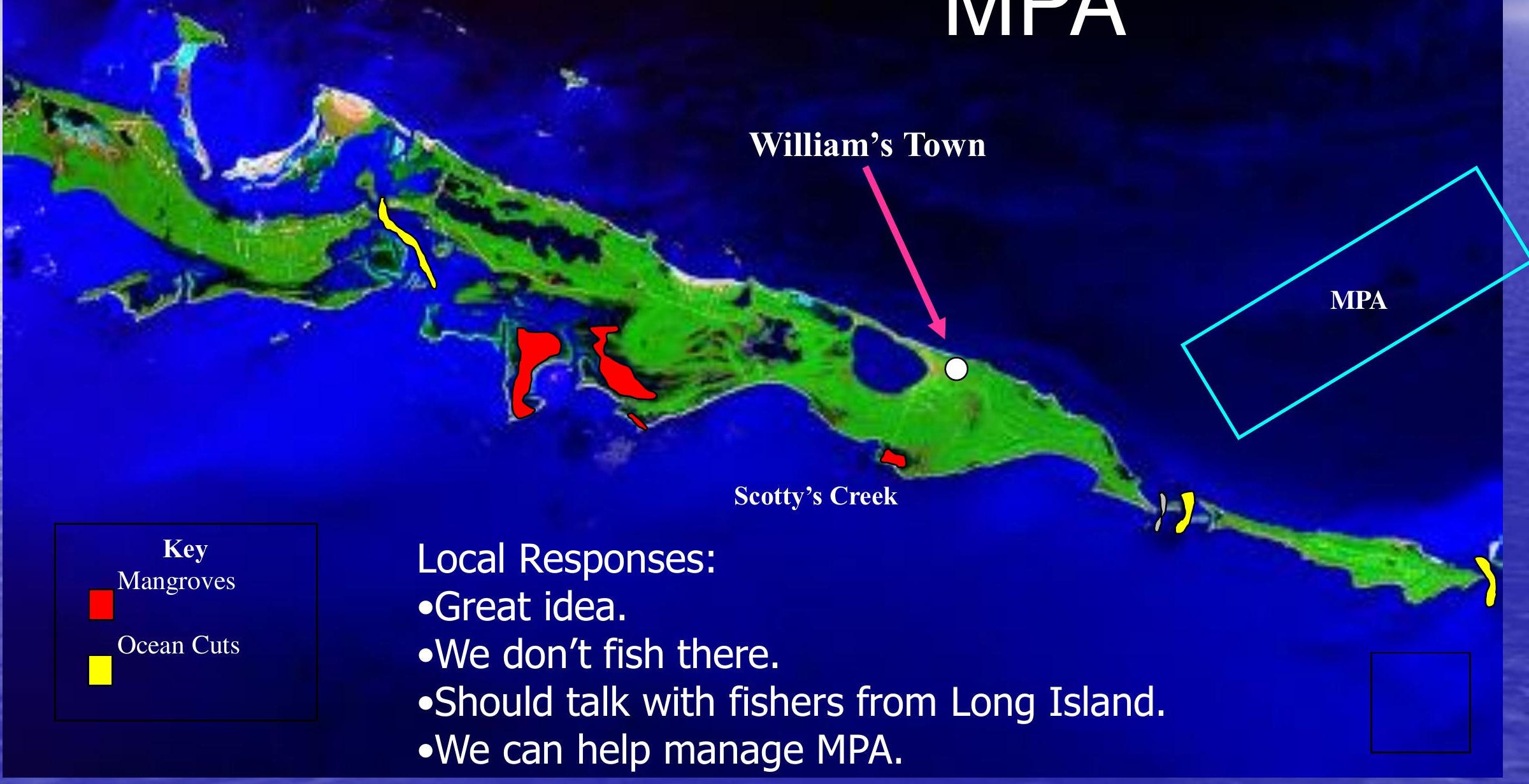




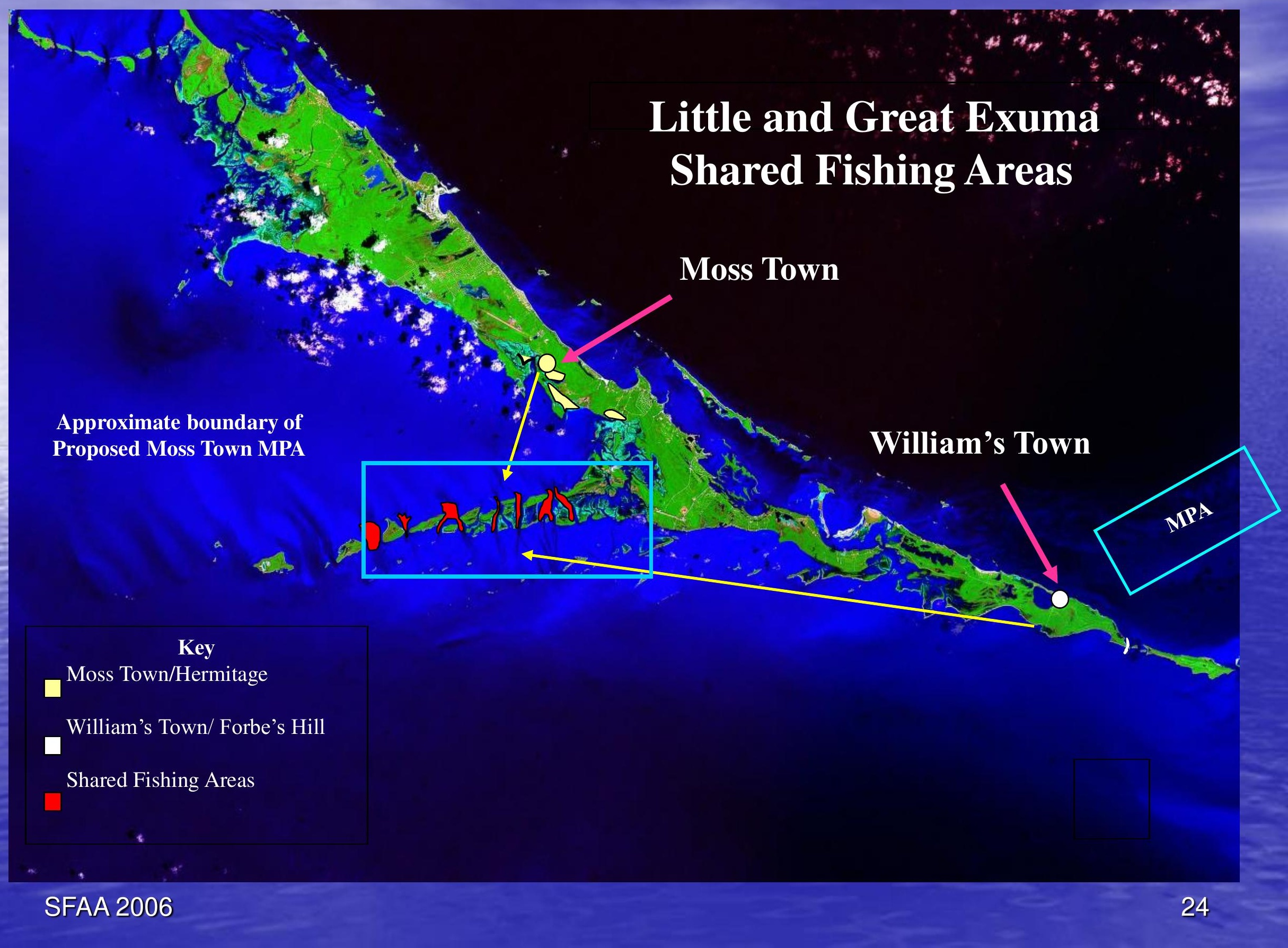




\section{Northern MPA}

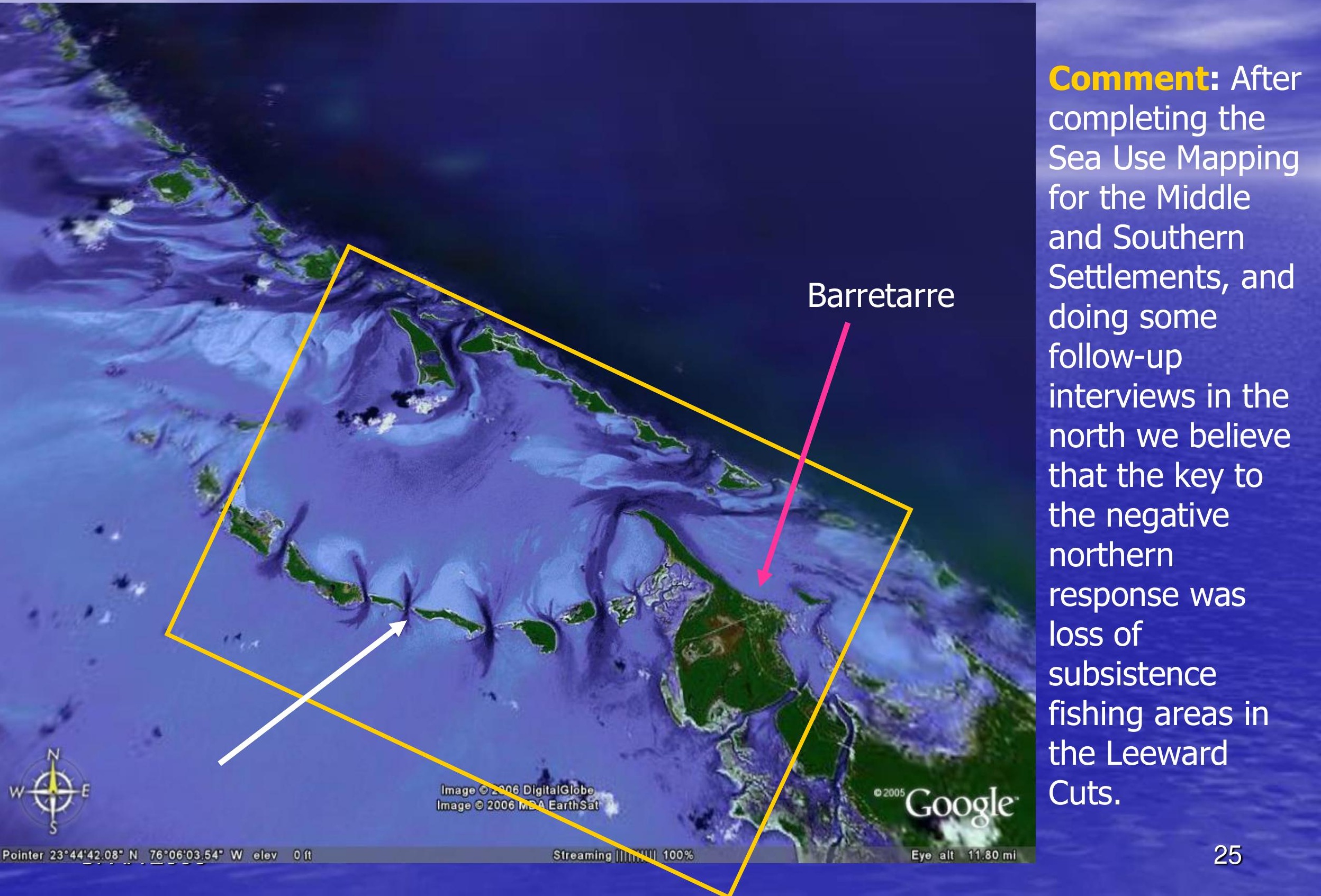




\section{Some Interesting Notions}

$\checkmark$ Since slavery the cay-cuts in the leeward portions of the ecosystem seem have macle and continue to contribute most to subsistence and small-scale cash transactions.

- There are marine products and then there is crawfish (Jobster), the later is really important to the local economy but rarely caught locally.

j Public meetings are a poor way to discuss public projects ljke MPAs, almost no one understood that the MPA would restrict locals from fishing.

- The people of the Exumas want MPAs where they are partners, monitors, and continue to have subsistence fishing - what was called in the ELSP the " take a meal" catch limit.

- The Bahamian Federal government can successfully establish MPAs in the Exumas. 